\title{
TECTAL PLATE TUMORS
}

\author{
Bruno C.R. Lázaro', José A. Landeiro²
}

\begin{abstract}
Tectal plate is a rare location for a tumor. Many papers have described different types of pathology arising in that location including tumors, vascular lesions, inflamatory and infectious processes. In this paper we describe our experience in treating seven patients with tectal plate lesions, with different ages and types of pathology: five patients presented with low grade gliomas, one with lung cancer metastasis and the last presenting with a tectal plate cavernoma. Open surg e ry was performed in three cases (due to tumor enlargement or need for the exact diagnosis). In the other cases, the treatment of non-comunicating hydrocephalus was the only treatment employed. The prognosis is of course dependent on the underlining pathology. In our series, except in the metastatic tumor case and the cavernoma, the other types of lesion consisted of low grade gliomas. These lesions represent a different type of brain stem tumor sharing a common good prognosis, with a benign behavior. We believe that tectal tumors must be managed case by case. When a patient presents with a benign lesions in the tectal region, treating the main symptom - hydrocephalus - should be the first attempt in management of these lesions.
\end{abstract}

KEY WORDS: brain stem, tectal tumors, brain stem tumors, third ventriculostomy.

\section{Tumores da região tectal}

RESUMO - Tumores na região do teto mesencefálico são raros. Vários tipos de lesões como tumores, lesões vasculare, inflamatórias e infecciosas localizam-se nesta região. Nós revimos o tratamento adotado em sete pacientes com diferentes tipos de lesões tectais: cinco pacientes apresentando gliomas de baixo grau, um paciente com lesão metastática proveniente de câncer de pulmão e um com cavernoma. $O$ tratamento cirúrgico com abordagem direta da lesão foi realizado em três casos (devido ao aumento do volume tumoral ou quando houve necessidade da confirmação diagnóstica). Nos demais casos o tratamento para a hidrocefalia não-comunicante foi o método empregado. O prognóstico dessas lesões é baseado no tipo de patologia em questão. Em nossa série, com exceção do caso de metástase e do paciente com cavemoma, as demais lesões foram gliomas de baixo grau. Estas lesões representam um subgrupo diferenciado de tumores de tronco encefálico, apresentando bom prognóstico e tendo comportamento benigno com sobrevida elevada. Acreditamos que tumores da região tectal devam ser avaliados caso a caso. Na hipótese diagnóstica de uma lesão benigna, o tratamento do principal complexo sindrômico - hidrocefalia não-comunicante - é provavelmente a melhor conduta a ser empregada.

PALAVRAS-CHAVE: tronco cerebral, tumores da região tectal, ventriculostomia.

Brain stem tumors are a wide described pathology. Most of the papers avaiable in the literature are of interest to the pediatric group. In general, it is accepted that brain stem tumors account for approximately $10-30 \%$ of brain tumors in children ${ }^{1-10}$. In these cases, three main groups are identifiable, according to location and prognosis. Diffuse pontine is the largest subgroup carryng a worst prognosis with a median survival of approximatelly one year; slow growing low grade gliomas comprise the second subgroup, arising at the cervicomedullary junction or from the floor of the $4^{\text {th }}$ ventricle baring a long survival rate - almost more than 5 years. The third subgroup is represented by focal tectal gliomas ${ }^{1}$.

On the other hand, brain stem tumors in adults especially gliomas - are poorly understood in terms of low incidence and diff e rent pattern of behavior. Over all, it is actually observed that the prognosis of brain stem tumors is better in adults than in children. The peak incidence prevailed in the third and fourth decade in adults and in the first decade in childre $\mathrm{n}^{2}$. Among tumors found in the tectal plate, the most common is the astrocytoma, but other types have been described, such as oligodendroglioma, ependy-

1Department of Neurosurgery, Brazilian Air Force Hospital, Rio de Janeiro, RJ, Brazil; 'M.D., Ph.D, Head of Department.

Received 4 October 2005, received in final form 16 January 2006. Accepted 17 February 2006

Dr. José A. Landeiro - Brazilian Air Force Hospital - Estrada do Galeão 4101 - Rio de Janeiro RJ - Brasil. E-mail: jlandeiro@aol.com 
moma, ganglioglioma, medulloblastoma ${ }^{3}$, primitive neu roectode mal tumors, metastasis; as well as lipo$\mathrm{ma}^{11}$, melanoma ${ }^{12}$, dysembryoplastic neuroepitelial tumor (DNT) ${ }^{13}$, cavernomas, abscess and periaqueductal gliosis.

We present seven cases of tumors arising in the tectal plate managed in our institution.

\section{METHOD}

We present seven cases of patients with mesencephalic tectal plate tumors treated in our institution, in a re trospective analysis, between $1994-2005$. There are $3 \mathrm{~m}$ ale and 4 female patients in this group with ages comprising 17 to 70 years-old.

Five patients presented Parinaud syndrome; all cases $p$ resented with noncommunicating hydrocephalus. Image studies were performed in all cases involving computed tomography scan (CT) and magnetic ressonance image (MRI) demonstrating lesions with the aspect of a low grade glioma in five cases, one case of high grade tumor (lung cancer metastasis), and the other presenting a vascular lesion (cavernoma).

The follow up period was over 8 years ( 1 to 8 years in average); open surgery was performed in 3 cases -2 cases (see ilustrative cases below), cavernoma and the metastasis case - obtaining a definitive diagnosis; third ventriculostomy was perf o rmed in the other fi ve cases (Table); in one case two procedures were necessary (see ilustrative cases below). There was one death - the metastatic tumor due to progressive disease (Table).

\section{Ilustrative cases}

Case 1 - A 26-year-old woman presented to our hospital with headache, nausea, papilledema and visual blurring. The CT scan revealed a noncommunicating hydrocephalus and a hypodense lesion on the tectal region (Fig 1). MRI demonstrated a tectal plate lesion (Fig 2) with lack of contrast enhancement.

She initially underwent ventricular-peritoneal shunt placement achieving adequate control and improvement of the symptoms, returning to normal activities and work afterwords.

One year later she returned to neurosurgical care presenting with worsening of the symptoms associated with incomplete Parinaud syndrome. A new MRI was performed and showed hydrocephalus and an increase of the lesion size (Fig 3). The shunt appeared to be malfunctioned. The tumor was removed using the semi-sitting position achieving a gross total removal of the lesion, as presented in MRI (Fig 4). She experienced an improvement of the symptoms, being discharged from the hospital one week later.

Histopatological analysis revealed a grade II astrocytoma.

Case 2 - A 24-year-old man was admitted with a history of somnolence, disorientation, headache and Parinaud syndrome. He had undergone placement of a ventricularperitoneal shunt 10 years before in another hospital for a diagnosis of "hydrocephalus" (history collected from his mother). A CT scan was performed showing a noncomunicating hydrocephalus. MRI was perf o rmed corrob or ating the diagnosis showing a T1 hypointense lesion located at the tectal plate.

Table 1. tectal tumors case reports.

\begin{tabular}{|c|c|c|c|c|c|c|}
\hline Patient & $\begin{array}{c}\text { Age } \\
\text { (years) }\end{array}$ & Gender & $\mathrm{CT}$ & MRI & Surgery & Diagnosis \\
\hline I & 24 & Male & Hydrocephalus & $\begin{array}{l}\text { Hydrocephalus } \\
\text { Tectal mass }\end{array}$ & $\begin{array}{l}\text { Third } \\
\text { Ventriculostomy }\end{array}$ & $\begin{array}{l}\text { Low grade glioma } \\
\text { (presumed) }\end{array}$ \\
\hline II & 26 & Female & $\begin{array}{l}\text { Hydrocephalus } \\
\text { Tectal low-density } \\
\text { image }\end{array}$ & $\begin{array}{l}\text { Hydrocephalus } \\
\text { Tectal mass }\end{array}$ & $\begin{array}{l}\text { CSF shunt } \\
\text { Tumor excision }\end{array}$ & \\
\hline III & 21 & Female & Hydrocephalus & $\begin{array}{l}\text { Hydrocephalus } \\
\text { Tectal mass }\end{array}$ & $\begin{array}{l}\text { Third } \\
\text { Ventriculostomy }\end{array}$ & $\begin{array}{l}\text { Low grade glioma } \\
\text { (presumed) }\end{array}$ \\
\hline IV & 16 & Female & Hydrocephalus & $\begin{array}{l}\text { Hydrocephalus } \\
\text { Tectal mass }\end{array}$ & $\begin{array}{l}\text { Third } \\
\text { Ventriculostomy }\end{array}$ & $\begin{array}{l}\text { Low grade glioma } \\
\text { (presumed) }\end{array}$ \\
\hline V & 17 & Male & Hydrocephalus & $\begin{array}{l}\text { Hydrocephalus } \\
\text { Tectal mass }\end{array}$ & $\begin{array}{l}\text { Third } \\
\text { Ventriculostomy }\end{array}$ & $\begin{array}{l}\text { Low grade glioma } \\
\text { (presumed) }\end{array}$ \\
\hline VI & 60 & Female & Hydrocephalus & $\begin{array}{l}\text { Enhancement } \\
\text { tectal mass }\end{array}$ & Tumor excision & $\begin{array}{l}\text { Cavernoma } \\
\text { Metastasis }\end{array}$ \\
\hline VII & 70 & Male & $\begin{array}{l}\text { Tectal } \\
\text { hyperdense lesion }\end{array}$ & $\begin{array}{l}\text { Hydrocephalus } \\
\text { Enhancement } \\
\text { tectal mass }\end{array}$ & $\begin{array}{l}\text { Third } \\
\text { Ventriculostomy } \\
\text { Tumor excision }\end{array}$ & \\
\hline
\end{tabular}




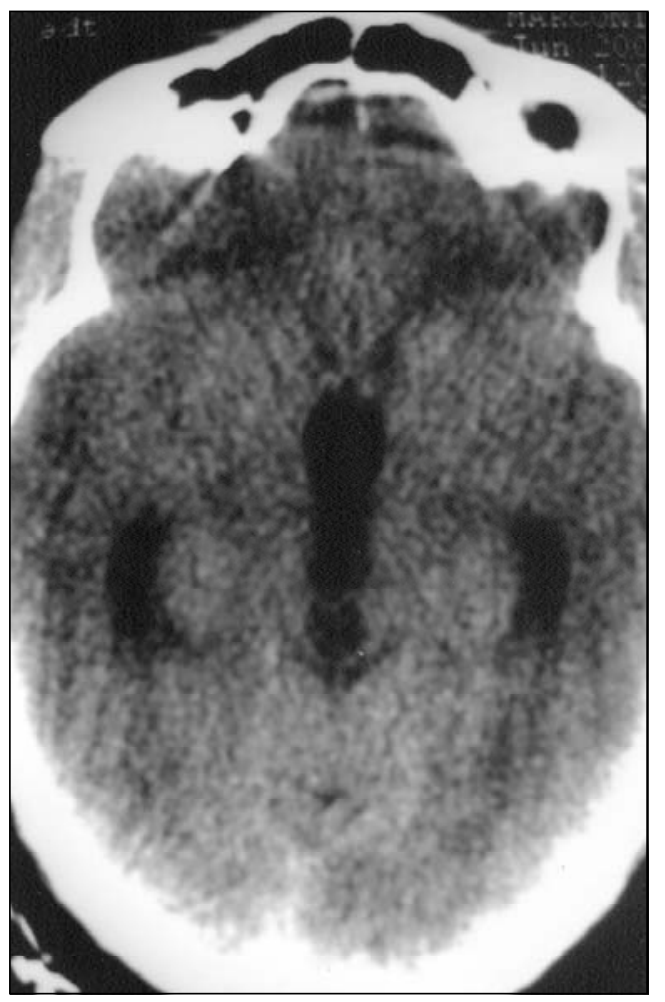

Fig 1. Brain CT scan in axial view presenting a noncommunicating hydrocephalus. Note the low-den sity lesion on the tectal plate.

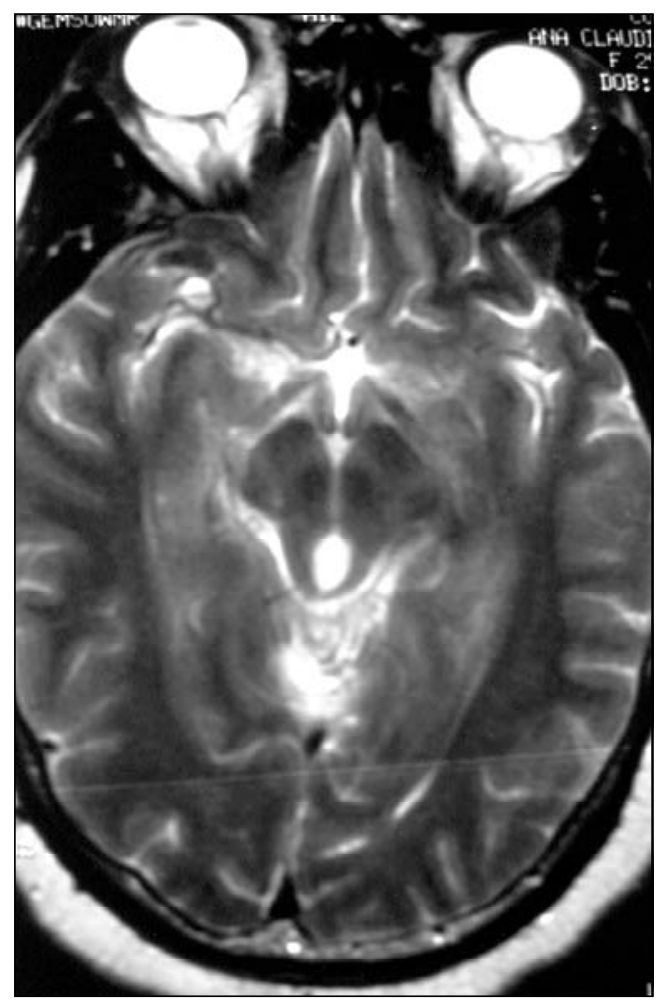

Fig 4. Postoperative MRI, T1 weighted sagital view, showing no gadolinium enhancement on the tec tal plate.

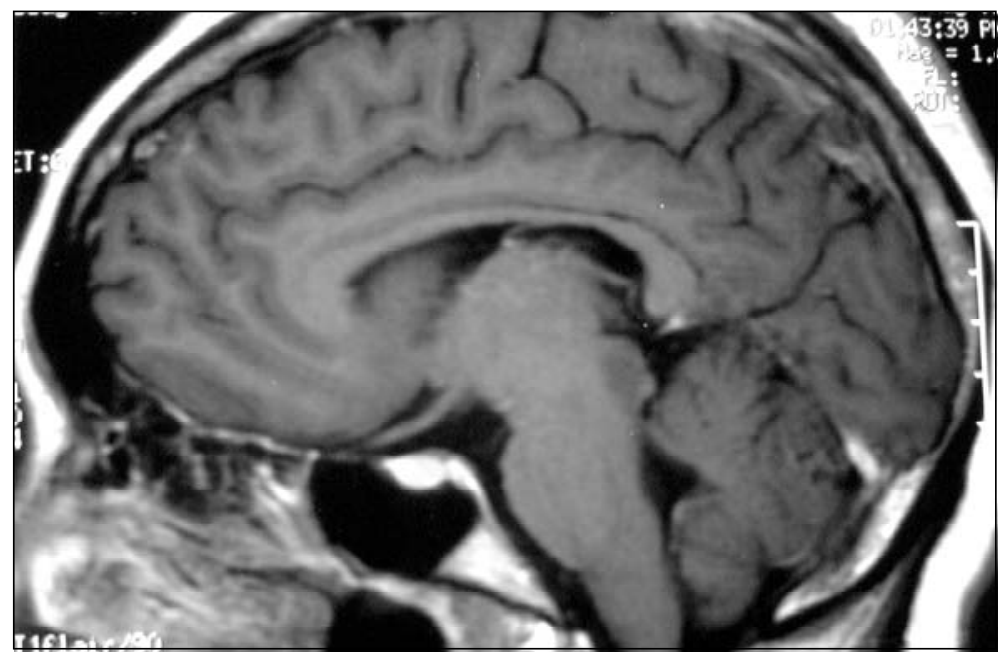

Fig 2. MRI, T1 weighted sagital view, showing a non-enhanced tectal mass.

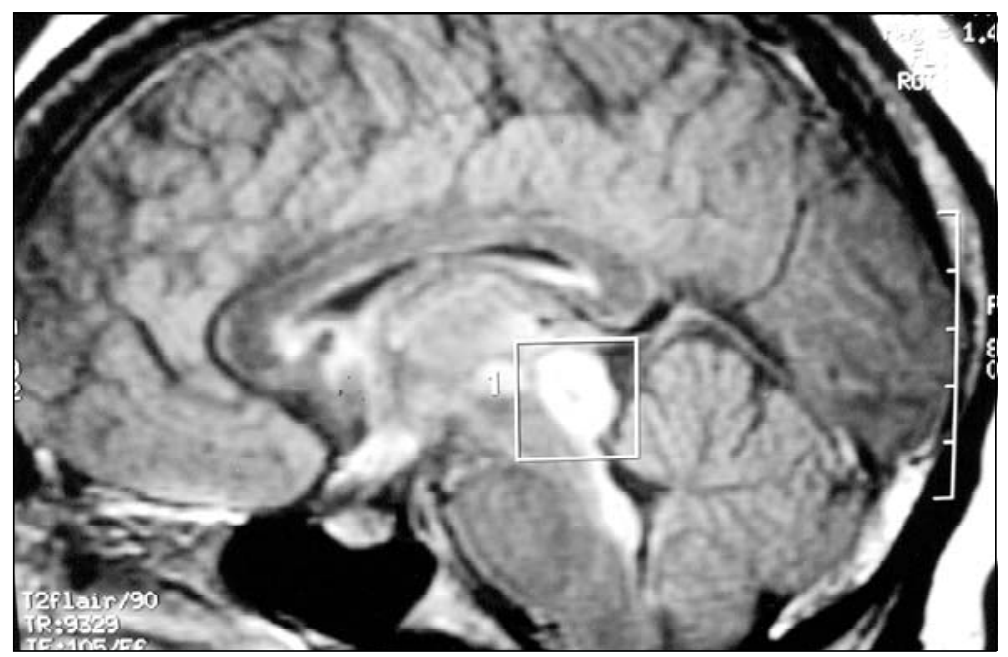

Fig 3. MRI sagital view, T2 FLAIR, presenting a tectal mass leading to obliter ation of the cerebral aqueduct.

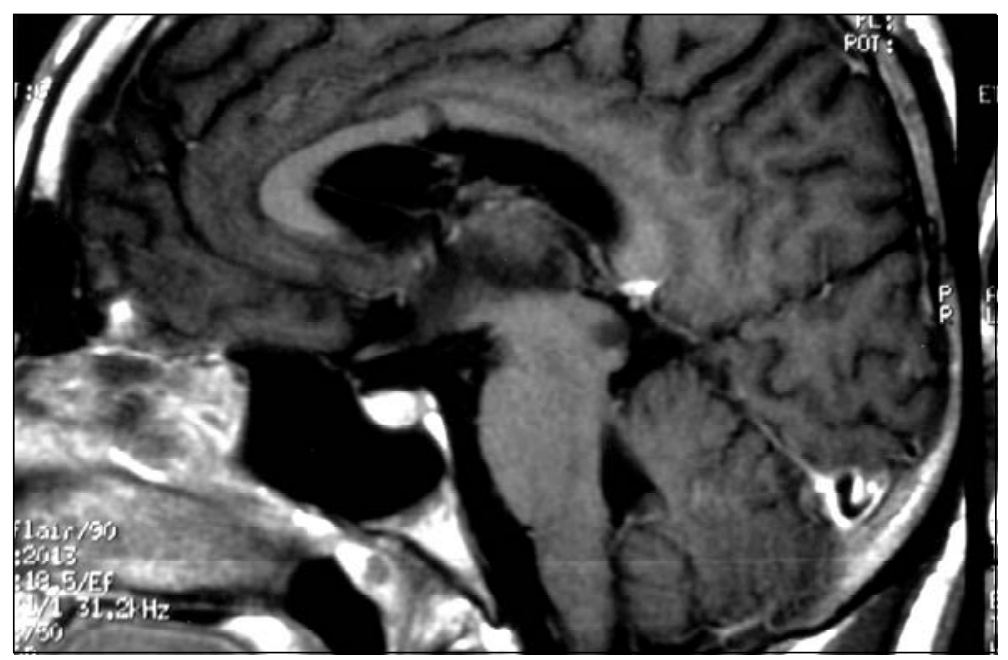

Fig 5. FLAIR T2 MRI, non-enhanced tectal mass leading to obliteration of the cerebral aqueduct. Note the corpus calosum tragetory of the neuroendo scope. 
He underwent an endoscopic third ventriculostomy with an imediate post opperative improving of the symptoms; the Parinaud syndrome was the last feature to disappear, occuring after one month. One year later he had reccurrence of the symptoms. A new radiologic study was performed showing once again a non-communicating hydrocephalus but the average size of the tectal tumor remained the same. A second third ventriculostomy was perf o rmed improving the symptomatology. He was discharged from the hospital 5 days after the procedure without symptoms (Fig 5).

\section{DISCUSSION}

In comparison to children, brain stem gliomas in adults is a less understood disease and present a much lower incidence ( $<2 \%$ of gliomas) ${ }^{1}$. The survival rate however can be very much longer with the peak incidence in the third and fourth decades ${ }^{2}$. The duration of symptoms is generally shorter in children while in adults it tends to be longer with tectal tumors, fourth ventricle dorsally exophytic tumors and cervicomedullarygliomas having a more favorable prognosis when compared to difuse lesions.

Tectal plate gliomas have been re ported as a particulary indolent lesion often remaining stable in size for many years. The majority of these lesions were described as low grade gliomas, presented with lateonset aqueductal stenosis often without associated brain stem signs ${ }^{8}$. The average age at the time of diagnosis is about 10 years in children, with the majority of cases presenting with raised intracranial pre ssure secondary to obstruction of the Sylvian aqueduct $^{14}$, with some other cases presented with Parinaud syndrome ${ }^{15}$ like the patients observed in our ilustrative cases, although this is also an uncommon feature. Even before the development of computed tomography, tectal tumors were an unrecognized because of late onset hydrocephalus ${ }^{6}$, once said that this can be the smallest lesion that can lead to death of the patient.

The radiologic investigation of these tumors have been up graded in the CT scan era with better visualization of the tectal region; but the majority of lesions continue to appear as noncommunicating hy$\mathrm{d}$ rocephalus alone, although calcification or a hypodense lesion on the tectal plate can be observed. MRI of these tumors reveals tectal distortion or thickning caused by a localized mass, leading to aqueductal compression and hydrocephalus ${ }^{16}$; characteristic T1 hypointensity and T2 hyperintensity ${ }^{17-21}$. MRI is an accurate and noninvasive method of diagnosis that can be indicated in all cases of late onset hydrocephalus and aqueductal obstruction, especially in adults.
Even when present, contrast enhancement after gadolinium injection was an independent factor of tumor grading ${ }^{17}$.

The characteristics of the lesion seen on the MRI is of course dependent on its pathologic basis. In our series we presented 5 cases of patients baring a tectal low grade glioma, with the typical MRI appearence just as described above. The other two cases - a brainstem metastasis and a tectal plate cavernoma appeared as an irregular enhancing lesion and a small vascular-like lesion presenting an impregnation of hemossiderin, respectivelly.

The prognosis of tectal plate lesion is a much debated issue in neuro s u rgical publications. It is reasonable to expect that a malignant lesion, brain stem metastasis and rapidally infiltrating lesions present a poor prognosis. But even in cases of tectal gliomas some controversies had arise.

Initially the pathology of intrinsic tectal lesions we re considered to be similar to other brainstem tumors. In fact this was later discovered as not true. Many papers have oriented the presence of this tumor as a special site of low grade gliomas $4-6,9,10,18$. These tumors appear to present a better prognosis given to a slow growing rate and boundaries displacement instead of an infiltrative behaviour. However, the management of the patients remains controversial. The majority of authors oriented the management including a mandatory histopatological analysis to acertain the low grade mark, and just afterwords the adequate treatment is traced. We think that the conjunction of history, age, neuro exam and MRI appearence of a tectal lesion can be very suspicious for a low grade tumor. In our cases, there is a tendency for treating the symptom - usually noncommunicating hydrocephalus - as the first option, but it is not always possible when there is a high suspicion of another type of tectal lesion, like the cavernoma and the lung cancer metastasis cases in our series.

Su rgical treatment consists on tumor resection or open biopsy; generally the surgical approach is that described for pineal region lesions, like the suboccipital-transtentorial or supracerebellar-infratentorial approach, prefered by this paper's senior author and routinelly performed in this institution adopting the semi-sitting position.

Ultimatelly, with the advance of neuroendoscopy, a new perspective in dealing with these lesions had arisen. When the objective is to treat the hydroce 
phalus, a rigid endoscope can be utilized to perf o rm a third ventriculostomy, as we described, with no major technical complications; the visibility of the inner surface of the third ventricle, with all structures involved is very good ${ }^{22}$.

Tectal tumors may extrude from the tectum into the lumen of the cerebral aqueduct and subsequently protrude to the third ventricle, pushing away the posterior commissure and enlarging the orifice. Some authors consider this lesion as intraventricular ones, treating each lesion individually ${ }^{23}$.

With the advent of the flexible neuroendoscope other types of therapy could be performed. Potential treatment options include shunt placement ${ }^{24}$ and aqueductal plasty ${ }^{24,25}$. The third ventriculostomy success and failure rate is similar to those cerebral-spinal fluid (CSF) shunts - about 30\% ${ }^{24}$.

In conclusion, tectal tumors re present a diffe rentiated category inneuro-oncology. Despite a variety of lesion encountered in this region, most publications indicate that low grade glioma is most prevalent. However, the major difficulty is regarding the adequate treatment of these lesions. A number of articles orients an invasive approach consisting of surgical treatment, given the need for mass reduction or just to obtain histopatological sample ${ }^{5,27,28 ;}$ other authors decline to conservative treatment, justified by the benign behavior and slow growth of this tumors ${ }^{4,6,8,19,29,30}$. In our institution, the decision depends on individual analysis. We give preference in treating the major symptom - hydrocephalus - with CSF shunts or preferably endoscopic third ventriculostomy. Our study demonstrate that surgery should be indicated when there is evidence of tumor enlargement or in cases when the definitive diagnosis is imperative.

Acknowledgement - We thank Igor de Castro M .D for editorial assistance and José Francisco Salomão M.D. for his support

\section{REFERENCES}

1. Guillamo JS, Monjour A, Taillandier L, et al. Brain stem gliomas in adults: prognostic factors and classification. Brain 2001;124:2528-2539.

2. Selvapandian S, Rajshekhar V, Chandy MJ. Brain stem glioma: comparative study of clinico-radiological presentation, pathology and outcome in children and adults. Acta Neurochir 1999;141:721-727.

3. Pollack IF, Hoffman HJ, Humphreys RP, Becker L. The long-term outcome after surgical treatment of dorsally exophytic brain stem gliomas. J Neurosurg 1993;78:859-863.
4. May PL, Blaser SI, Hoffman HL, et al. Benign intrinsic tectal "tumors" in children. J Neurosurg 1991;74:867-871.

5. Lapras CI,. Bognar L, Turjman E, et al. Tectal plate gliomas. Part I: microsurgery of the tectal plate gliomas. Acta Neurochir 1994;126:76-83.

6. Yeh DD, Warnick RE, Ernst RJ. Management strategy for adult patients with dorsal midbrain gliomas. Neurosurgery 2002;50:740.

7. Epstein FJ, Farmer JP. Brain stem glioma growth patterns. J Neurosurg 1993;78:408-412.

8. Pollack IF, Pang D, Albright AL. The long term outcome in children with late-onset aqueductal stenosis resulting from benign intrinsic tectal tumors. J Neurosurg 1994;80:681-688.

9. Vandertop WP, Hoffman HJ, Drake JM, et al. Focal midbrain tumors in children. Neurosurgery 1992;31:186-194.

10. Wang C, Zhang J, Liu A, et al. Surgical treatment of primary midbrain gliomas. Surg Neurol 2000;53:41-51.

11. Uchino A, Hasuo K, Matsumoto S, Masuda K. MRI of dorsal mesensephalic lipomas. Clin Imaging 1993;17:12-16.

12. Weiding SM, Press GA, HasselinkJR. Am J Neuroradiol 1988;9:214-215.

13. Kurtkaya-Yapicier O, Elmaci I, Boran B, et al. Dysembrioplastic neuroepithelial tumor of the midbrain tectum: a case report. Brain Tumor Pathol 2002;19:97-100.

14. Gomez-Gonsalvez FA, Menor F, Morant A, et al. Tectal tumors in paediatrics. A review of eight patients. Rev Neurol 2001;33:605-611.

15. Moffie D, Ongerboer de Visser BW, Stefanko SZ. Parinaud syndrome. J Neurol Sci 1983;58:175-183.

16. Antunes NL, Tavora L, Souweidane M. Globular glioma of the tectum. Pediatr Neurol 1999;21:492-495.

17. Bognar L, Turjman F, Villanyi E, et al. Tectal plate gliomas Part II: CT scans and MRI imaging of tectal gliomas. Acta Neurochir 1994;127: 48-54.

18. Ramina R, Neto MC, Fernandes $Y B$ et al. Intrinsic tectal low grade astrocytomas. Arq Neuropsiquiatr 2005;63:40-45.

19. Bowers DC, Georgiades C, A ronson LJ et al. Tectal gliomas: natural history of an indolent lesion in pediatric patients. Pediatr Neurosurg 2000; 32:265-271.

20. Hamilton MG, Lauryssen C, Hagen N. Focal midbrain glioma: long term survival in a cohort of 16 patients and the implications for management. Can J Neurol Sci 1996;23:204-207.

21. Smith RR, Zimmerman RA, PackerRJ et al. Pediatric brain stem glioma; post-radiation clinical and radiographic follow-up. Neuroradiology 1990;32:265-271.

22. Oka K, Go Y, Kin Y, Tomonaga M. An observation of the third ventricle under flexible fiberoptic ventriculoscope: normal structure Surg Neurol 1993;40:273-277.

23. Oka K, Kin Y, Go Y, et al. Neuroendoscopic approach to tectal tumors: a consecutive series. J Neurosurg 1999;91:964-970.

24. Bulsara KR, Villavicencio AT, Shah AJ, et al. Successful aqueductal plasty and stenting for tectal plate tumor after failed third ventricuostomy: a case report. Surg Neurol 2003;59:58-62.

25. Oka K, Yamamoto M, Ikeda K, Tomonaga M. Flexible endoneurosurgical therapy for aqueductal stenosis. Neurosurgery 1993;33:236-242.

26. Schroder HW, Gaab MR. Endoscopic aqueductoplasty. Neurosurgery 1999;45:508-517.

27. Koziarsky A, Zielinski G, Podgorski JK, Wa rczynska A. One stage removal of periaqueductal glioma in adult via infratentorial supracerebellar and transaqueductal approaches. Acta Neurochir 2004;146:169173.

28. Robertson PL, Muraszko KM, Brumberg JA, Axtell RA, Dauser RC, Turrisi AT. Pediatric midbrain tumors: a benign subgroup of brain stem gliomas. Pediatr Neurosurg 1995;22:65-73.

29. Squires LA, Allen JC, Abbot R, Epstein FJ. Focal tectac tumors: management and prognosis. Neurology 1994;44:953-956.

30. Daglioglu E, Cataltepe O, Akalan N. Tectal gliomas in children: the implications for natural history and management strategy. Pediatr Neurosurg 2003;38:223-231. 